' roaring forties' of mariners." He further directs attention to the need of distinguishing between these two weather systems, which play distinct parts in the meteorology of this region. A study of the accompanying two figures will. indicate the importance of the islands of Tristan d'Acunha and Gough (indicated by a black dot towards the south-west), and also of Mauritius (the dot east of Madagascar). The two former islands lie in the wind sýstem pertaining to the anticyclonic (high-pressure) area on the west, the centre being indicated by the letter $\mathrm{H}$, while Mauritius, situated to the east of South Africa, is in the south-east trade area in the system formed by the high-pressure (anticyclonic) region, the centre of which is marked also with an $\mathrm{H}$.

By observing the general trend of the air currents indicated by the large arrow, it will be seen that for the winter season in South Africa (Fig. I) meteorological observations made in either Tristan d'Acunhà or Gough Islands would undoubtedly render valuable aid to the weather forecasters.

In the case of the summer months (Fig. 2) there is no conveniently placed island that could furnish equal assistance, but it seems very possible that use could be, and most probably has been, made of the observations at Mauritius for determining the strength of the south-east trade current which impinges on the African coast at this time of year. For forecasting purposes Mauritius, and possibly Rodrigues, would have greater value for regions further up the African coast.

Infortunately, the Amsterdam and St. Paul islands (marked with one dot) lie too far south and east to serve as useful outlying stations for South Africa. On the other hand, these islands should be undoubtedly utilised by the Australians.

An examination of the accompanying figures indicates the relative positions of the Australian continent and this large southern Indian Ocean wind system. These islands will thus be seen to be right in the track of the current which strikes the south and west coasts of Australia, and should form ideal out-stations for gauging the general condition of this wind system.

That the prevailing winds on the west coast of Australia come from a southerly direction is indicated in the following table, which gives the number of times the wind has blown from each point of the compass at the Perth Observatory during the year 1902 , the readings being taken eight times a day :-

\begin{tabular}{|c|c|c|c|c|c|}
\hline N. $\quad \ldots$ & $\cdots$ & $\cdots$ & $\cdots$ & $\cdots$ & $\cdots$ \\
\hline N.N.W. & $\cdots$ & $\cdots$ & $\cdots$ & $\cdots$ & $\cdots$ \\
\hline N.W. $\quad \cdots$ & $\cdots$ & $\cdots$ & $\cdots$ & $\cdots$ & $\cdots$ \\
\hline W.N.W. & $\cdots$ & $\cdots$ & $\cdots$ & $\cdots$ & $\cdots$ \\
\hline W.S.w. & & $\cdots$ & $\cdots$ & $\cdots$ & \\
\hline S.W. $\ldots$ & $\begin{array}{l}\cdots \\
\ldots\end{array}$ & $\begin{array}{l}\cdots \\
\ldots\end{array}$ & $\cdots$ & $\cdots$ & $\cdots$ \\
\hline S.S.W $\quad \ldots$ & $\ldots$ & $\ldots$ & $\cdots$ & $\cdots$ & $\cdots$ \\
\hline$\cdots$ & $\cdots$ & $\cdots$ & $\cdots$ & $\cdots$ & $\cdots$ \\
\hline S.S.E. $\cdots$ & $\cdots$ & $\cdots$ & $\cdots$ & $\cdots$ & $\cdots$ \\
\hline $\begin{array}{l}\text { S.E. } \\
\text { E.S.E. } \cdots\end{array}$ & $\cdots$ & $\cdots$ & $\cdots$ & $\cdots$ & $\cdots$ \\
\hline $\begin{array}{ll}\text { E.S.E. } & \cdots \\
\text { E. } & \cdots\end{array}$ & $\cdots$ & $\cdots$ & $\cdots$ & $\cdots$ & $\cdots$ \\
\hline $\begin{array}{l}\text { E.N.E. } \cdots \\
\cdots\end{array}$ & $\cdots$ & $\cdots$ & $\cdots$ & $\cdots$ & $\cdots$ \\
\hline & $\cdots$ & $\cdots$ & $\ldots$ & $\cdots$ & $\cdots$ \\
\hline N.N.E. & $\ldots$ & $\ldots$ & $\ldots$ & $\ldots$ & $\ldots$ \\
\hline
\end{tabular}

Another table shows that the resultant direction of the wind, at the same observatory for the same year, was south for the months January to April and October to December inclusive.

There seems every reason, then, to hope that the utilisation of information from one of these islands for several months in the year would in time amply repay the initial cost and maintenance of the station.

It is not without interest to remark that the air current which passes the west coast of Australia in July (that is, in winter in Australia) becomes later the south-east trade wind of the Indian Ocean, and eventually reaches the Indian area in the form of the south-west monsoon in the summer months of the northern hemisphere. In the months about July, Western Australia is thus apparently closely connected, meteorologically speaking, with India, NO. 1857 , VOL. 72$]$ but in the months about January the connection is between Australia and South Africa.

The natural deduction to be made from the above is that the meteorological services of all these countries should be closely in touch with each other. Their combined efforts will certainly considerably increase our knowledge of the meteorology of this vast region, and each will benefit by this mutual interchange of information.

Although mention has only been made of one or two instances in which the employment of islands as meteorological stations would most probably be rewarded with practical results, there are other countries that might equally profit by adopting the same principle.

It is, however, important for the study of world meteorology that many islands should be employed as observing stations. They may not be very ideal places for observers to live in, but a change every few months, and the adoption of self-recording instruments, would possibly simplify matters. Where cables are lacking, and the island in question is of great meteorological importance to some continent, wireless telegraphy might be employed with advantage.

WILLIAM J. S. LOCKYER

\section{AN OPTICAL CONGRESS AND EXHIBITION}

$T^{r} \mathrm{IE}$ aims of the optical convention, which was opened at the Northampton Institute, Clerkenwell, on Tuesday, May 30 , are to increase the interest taken in optical science in this country, to promote an improvement in technical education in optical matters, and to aid the development of the British optical industry. In his address, the chief part of which is subjoined, the president, Dr. R. T. Glazebrook, F.R.S., after explaining the origin of the proposal to hold a convention, and the steps taken to realise it, gives an outline of the history of optical progress during the past two hundred and fifty years with the view of illustrating the close union which has existed between theory and practice' at times of marked progress, and of showing how each has reacted on the other in assisting this progress. The programme of the convention includes meetings for papers and discussions, which will be subsequently published in a volume, and an exhibition of optical and scientific instruments of British manufacture, with a catalogue which is intended to serve as a work of reference illustrating the productions of opticians in this country. A description of some of the exhibits follows the president's address abridged below; and an article on the nature and matter of the papers and discussions will appear in these pages after the close of the convention.

Prugress of Optical Science and Manufactures.

The study of optics is a fascinating one, and its history full of interest. I do not propose to-night to attempt to cover the whole ground, but to ask you to look at one or two special periods during which, it seems to me, theory and practice reacted on each other in a marked manner and to consider what lessons we may draw as to the relation which should in these days of ours subsist between the two.

For this purpose I might go back to very early days. Ptolemy in his attempt to discover the laws of refraction -and wonderfully good the attempt was, as we know now -Archimedes with his burning glass, if, indeed, he ever made it, had both practical aims in view. But we will start to-night nearer our own. time. The end of the seventeenth century is such a period. The telescope was invented about 1608 , the microscope at rather an earlier date, about 1590 , both, probably, in Holland.

Galileo, hearing of this, made his first telescope in I6 Io. In r6rr Kepler, in his "Dioptrica," described the astronomical telescope with one or more convex lenses as the eye-piece; with this exception, up to Descartes's book on "Dioptrics" in 1637, no other form of telescope but Galileo's was known. The law of refraction was first enunciated by Snell in $162 \mathrm{r}$.

Thus by the year 1660 the importance of the telescope to the astronomer was fully appreciated, and its limitations were being realised. In I663 Gregory published an account

1 From the inaugural address delivered before the Optical Convention on May 30 by the president, Dr. R. T. Glazebrook, F.R.S. 
of the first reflecting telescope designed to meet some of these defects, and about this time two men, whose work has left indelible marks on the science, were led to study it in a great measure from their interest in astronomyChristian Huyghens, who lived from 1629 to 1695 , and Isaac Newton, 1642 to 1727 .

Huyghens was the discoverer of the wave theory and of the law of double refraction, but he was also a skilled mechanic, and he worked himself at grinding his lenses and erecting his telescopes. He realised from a consideration of the theory that many of the most marked defects were due to the fact that the rays from a distant star traversing the various parts of the lens were not brought to a focus at the same point on the axis, and that for a lens of given aperture this axial aberration decreased rapidly as the focal length increased. The magnification of the telescope depends on the ratio of the focal length of the object glass to that of the eye-piece. Hence by keeping this ratio constant, and increasing both focal lengths in the same proportion, the magnification could be maintained and the spherical aberration decreased.

Thus he was led to make lenses of 120 feet focal length. Tubes for such instruments could not be produced, and they were mounted on the top of tall poles and moved from below by ropes. With one of these telescopes, which he afterwards presented to the Royal Society, he discovered Saturn's rings and its fourth satellite. In this case the desire to improve an instrument caused an appeal to theory, and theory led the optician to make a real advance. The advance, it is true, was an inconvenient one, and the defects, as we shall see, were not entirely due to spherical aberration, but the fact remains.

In another branch of instrument making Huyghens is famous for applying science to manufacture. His treatise "Horologium Oscillatorium," which discussed most ably many problems of motion, was long the standard work on clocks, and he was the first to bring into practical use, in I657, the pendulum as a regulator for time measurements, though according to Sir E. Beckett the first pendulum clock actually made was constructed in 1621 by Harris, of London, for St. Paul's Church, Covent Garden.

In 1665 a posthumous work of an Italian Jesuit, Francis Maris Grimaldi, entitled "Physico Mathesis de Lumine, Coloribus et Iride aliisque annexis," was published at Bologna. It contains some notable observations, particularly the discovery of diffraction.

Newton, who in the previous year had taken his B.A. degree at Cambridge, purchased a prism at Stourbridge Fair in 1666 " to try therewith the celebrated phenomena of colours," and to repeat some of Grimaldi's experiments. During that year also he had applied himself to the grinding of " Optic Glasses of other figures than spherical." $\mathrm{He}$ was already interested in astronomy, possibly had already made, but not confirmed, his great discovery. Writing to Halley in 1686 about some of the controversies which followed the publication of the "Principia," he says :- "But for the duplicate proportion I gathered it from Kepler's theorem about twenty years ago."

The celebrated apple is supposed to have fallen in his mother's garden at Woolsthorpe, in Lincolnshire, in 1665 , where he was driven by the plague, and the story has some authority. It is stated to be the fact by Conduitt, the husband of Newton's favourite niece; it was told by Mrs. Conduitt to Voltaire, and the tree from which it was said to have fallen was seen by Sir David Brewster in 1820 .

Various suggestions have been made, for the reason why the discovery that the same cause which produced the apple's fall also maintained the moon in her orbit was not published for many years; the true one is probably due to Dr. Glaisher, who pointed out that it was necessary to know the attraction not merely between two particles of matter, but between two spherical bodies of large size, and that this problem was not solved until much later; but, be this as it may, we are sure that in 1667 Newton was an astronomer, and realised the necessity for accurate astronomical observations, and all that the improvement of the telescope meant to astronomers.

Now his experiments with the prism in I666 led to the discovery of the spectrum; little was known about colours at that time, and Dr. Barrow's "Treatise on Optics," published with Newton's help in $1669_{1}$ contains very erroneous views; but some time shortly after that date Newton was able to draw the important conclusion that white light is not homogeneous, but consists of rays some of which are more refrangible than others; the pictures of the spectrum, so familiar to us in numerous text-books, come from Newton's "Optics," published first in 1704, though his discoveries as to the analysis of white light were laid before the Royal Society in various papers in 1671 , and were given in lectures on optics as Lucasian professor in Cambridge in 1669,1670 , and $167 \mathrm{r}$.

The bearing of all these physical experiments and researches on the practical manufacture of the telescope was at once obvious; the lenses behave like prisms, and decompose the light into its constituent colours. No alteration of shape will remove this entirely, and Newton was driven, too hastily as we know now, to the conclusion that the refracting telescope could not be greatly improved; its defects were inherent in the refraction of light.

The defect, however, does not exist in images formed by reflection, and he came to the conclusion that optical instruments might be brought to any degree of perfection imaginable provided a reflecting surface could be found which would polish as freely as glass and reflect as much light as glass transmits, and provided a method of communicating to it a parabolic figure could be found. In I 668 he thought of a delicate method of polishing by which he believed "the figure would be corrected to the last," and the Newtonian reflecting telescope was the result. An instrument made with his own hands is now in the possession of the Royal Society, and the many noble instruments which have added so greatly to advance our knowledge of the stars are the direct outcome of Newton's experiments with the prism and the deductions he drew from them.

But these experiments convey another lesson, for Newton, misled by his observations on dispersion, decided, wrongly, as we know now, that achromatic lenses were impossible, and that the colour defects must always exist in reflecting instruments; and as a result attempts to improve these instruments were almost in abeyance for nearly ninety years. Two or three achromatic telescopes were made by Mr. Hall about 1730 , but it was not until 1757 that Dollond re-invented this instrument and commenced the regular construction of such lenses.

Thus the discoveries of Huyghens and of Newton reacted powerfully on the instruments of their day Indeed, in each of these two instances the discoverer and the instrument maker were the same person. Such a combination may be less possible now; still, there are mathematicians skilled in the theory of optics and opticians skilled in the practice of their art.

The Optical Convention aims at coordinating the efforts of the two. But if 200 years ago the progress of the telescope was determined by the advance of optical theory, theory itself was no less indebted to the interest in instruments and observations thus aroused for the progress that took place.

Huyghens was the founder of the wave theory, though the labours of Young and the genius of Fresnel were necessary before Newton's rival theory of emission was displaced.

For nearly 100 years after the date of Newton's "Optics" progress was slow. The world was occupied in assimilating what he had taught. English mathematicians, overawed, perhaps, by his transcendent greatness, employed themselves in expounding his teaching. In England, at any rate, the emission theory was supreme, and few, if any, questioned his dicta as to the impossibility of achromatism.

But a change came with the new century. Thomas Young, $1773^{-1829}$, was the first in his various papers between 1801 and 1811 again to direct attention to Huyghens's work, and to place on a firmer basis the ground-work of the wave theory. $\mathrm{He}$ it was who established clearly the principle of the superposition of waves, and showed how interference may be explained by it.

Young's work, however, would have been incomplete without Fresnel (1788-1827), who re-discovered for himself the principle of interference and extended it to explain diffraction, besides enunciating his theory of double re- 
fraction and deducing the well known expressions for the intensity of the light reflected from or transmitted by a transparent surface.

Young, in his "Lectures on Natural Philosophy," illustrated in an admirable way the applications of optical theory to instruments. Fresnel was an engineer by profession attached to the service of the bridges and roads, and as such was the inventor of the arrangements of lenses employed in the French lighthouses.

The discoveries of these two men changed the whole of the theory on which the construction of optical instruments is based; it is idle to attempt to explain the action of a microscope, the resolution of a double star or of the fine lines of the spectrum, to discuss the conditions for such resolution, or, instead, to attempt the construction of any of the more delicate of the beautiful apparatus about us without clearly understanding the fundamental laws discovered by these two, and verified with marvellous skill by Fresnel in his country home in Normandy, not by the aid of modern apparatus, but by such means as his own hands, aided by the skill of the village blacksmith, could construct; and though it is true that only recently have we appreciated the full importance of the wave theory in its bearing on the construction of optical instruments, it is the fact that without their labours and the work of those who followed in their path few of the modern discoveries of the astronomer, few of the results which the skilled optician of to-day has arrived at, would have been possible. The object glass of a microscope, the lens of a camera or a telescope, have reached their present perfection because men have been found who could apply to the art of lens grinding the highest teaching of Young and of Fresnel.

In the earlier years of the last century Englishmen were well to the fore in this work. In astronomy the labours of the two Herschels are well known, and though, perhaps, the success of the elder Herschel was due rather to his mechanical skill than to a profound knowledge of optical theory, Sir John Herschel advanced in no small measure the application of theory to practice.

At a somewhat earlier date Fraunhofer, of Munich (1787-1826), a contemporary of Young and of Fresnel, had realised the fact that the development of the achromatic lens " depended on the exact determination of refractive indices, and that the chief difficulty in that determination lay in the difficulty of obtaining homogeneous radiations to serve as standards" (Schüster, "Theory of Optics").

For these he used the dark lines of the solar spectrum, originally observed by. Wollaston, and in this we have an example of the manner in which practical needs react to assist in the advance of science, for from these observations springs the whole of spectrum analysis and all that is involved in that.

Thus theory and practice progress together; each alone carries us but a short way, but the judicious use of hypothesis and reason, supported by the verdict of experiment, carries us on to new knowledge, and brings us nearer to the truth.

Until after the middle of last century we in Britain took our full share in promoting this advance. We might add to the names already mentioned those of Sir George Airy and of the distinguished men who, in the first half of the century, adorned Trinity College, Dublin, notably Sir William Hamilton.

Sir George Airy gave, abour 1802, an account of the aberration of the lens of the camera obscura of the utmost value to the early designers of the photographic lens, while Sir William Hamilton's essay on the "Theory of Systems of Rays" contains the essence of all that is needed to calculate to a high degree of accuracy the aberration of such a lens.

But at that date photographic lenses were not thought of, and when Daguerre announced his invention in 1839 the work of Airy and of Hamilton was forgotten. Thus to quote, as I did lately in the Traill Taylor lecture, from the recent work of Dr. M. von Rohr.

"The important signification of Airy's writings for photographic optics does not seem to have been appreciated until a later date. Although they exercised an influence on English text-hooks, like that of Coddington, they seem

$$
\text { No. I } 857 \text {, VOL. } 72]
$$

unfortunately never to have become known in wider circles on the Continent. It appears, then, that the theoretical opticians of later years to whom his investigations into the astigmatic deformations of oblique pencils would have been of great interest did not base their work on that of Sir G. B. Airy," while Sir W. Hamilton's paper remained unnoticed by the optician until Finsterwalder directed attention to it, and another distinguished German, Prof, Thiessen, quite lately put his results into an accessible form.

There was a divorce between theory and practice in England. The importance of Daguerre's discovery was at once realised, and English opticians set to work with no small success to develop the lens and to make it perfect, and splendidly in many ways they performed their task; but the work was empirical. : A certain amount of progress was possible, and was achieved, but without the guidance of well founded theory the progress could not be for long.

The learned Transactions of the Cambridge Philosophical Society and of the Royal Society of Dublin were perhaps the last places to which the practical optician would apply for help, and so it came about that because the opticians of another nation first recognised that a full knowledge of the action of a lens on the light that traverses it was a condition precedent to further truth for some years past the great improvements in the products of the optician's skill which have taken place have had their origin mainly in Germany.

This brings me to our last example of the manner in which science and practice may combine to produce effects unattainable by either singly. But before dealing with this I would mention one great advantage which, until a few years ago, the English optician possessed in a special degree, an advantage to which much of the progress of our English lenses is undoubtedly due. The story of Gunand's invention of optical glass is deeply interesting. A poor carpenter, and later a watch-case maker; of Brenetz, in canton Neuchatel, he was born in 1740 , and became at an early age interested in telescopes. Prompted by the desire tu possess a pair of spectacles, he undertook to make the glass for the lenses. A little later, through M. Droz, a gentleman of the neighbourhood, he was allowed to examine one of Dolland's achromatic lenses, and learnt of the difficulty of obtaining the flint glass required. This he determined to make, and years of penury and unremitting toil followed, until at last he succeeded in casting discs sufficiently homogeneous to be ised for optical work.

Fraunhofer persuaded him to migrate to Munich, but the venture was not a success. He returned to Switzerland, and again started glass making. After his death his son told the secret of the art to George Boutemps, a Frenchman, who some years later was brought to England by Messrs. Chance, and helped them to establish the optical glass works which for so long were practically the sole source of the supply of raw material for the optician.

Our catalogue to-day bears witness to the progress in glass manufacture that has taken place since Boutemps's time, and it is right to recognise the influence that progress has had on opticians' work.

But to return to our main subject. An optical convention in 1905 would be incomplete without some reference to the work of that master optician who a few months ago was taken from us, the more so since the work of Ernst Abbe affords perhaps the most striking illustration of the effects of the reasoned combination of theory and practice. A comparison of the statistics of the optical trade of Germany now and twenty years ago will suffice to prove this.

The story of the growth of the Jena industry has been told frequently, still I will repeat it in barest outline. Abbe, then a young man, had settled at Jena as a privat docent in 1863 , and soon after Carl Zeiss, who then made microscopes of the ordinary class, applied to him for help in the development of the instrument. Abbe's task was a hard one; the theory of the microscope was at that date only partially understood, the corrections to the lenses were made by a rough trial and error method, and the results were doubtful. The first step was to solve a mathematical problem of no small difficulty, to trace the paths 
of the pencil through the object glass. Abbe soon realised the defects of the ordinary theory. He found it necessary to apply the principles of the wave theory, the teaching of Young and Fresnel, to the problem, and was led in 1870 to the theory of microscopic vision which bears his name. His work was the direct outcome of that of Fresnel.

$\mathrm{He}$ soon realised that it followed from the mathematical theory that with the glass then at the optician's disposal no great improvement in the microscope object glass could be expected. Certain relations between the dispersion and refraction in the various lenses were requisite to secure achromatism, and no glass having these relations existed. An inspection of the instruments in our loan exhibition at South Kensington in 1876 confirmed this view, and he published it in a report in 1878 on the results of the exhibition:- "The future of the Microscope as regards its future improvement in its dioptric qualities seems to be chiefly in the hands of the glass maker."

The investigations of Petzval and of von Seidel led to a similar result with regard to photographic lenses. Von Seidel's work dates back to $1856-7$, but his main paper was not written until 1880, after the date of Abbe's report, and was not published in full until 1898 .

It follows from these investigations that with the glass then on the market it was impossible to make the field of a photographic lens at once flat and achromatic.

Thus the theoretical work indicated a bar to future progress which could only be removed by the manufacture of new glasses having certain definite properties. It is fitting to say that at an earlier date this fact had been recognised by our countrymen Mr. Vernon Harcourt and Prof. Stokes, who for some eight years previous to 1870 had endeavoured, but with scant success, to make the glass required.

Abbe was more fortunate; his report fell into the hands of Dr. Otto Schott, a glass maker of Witten, in Westphalia, who realised its importance. In 188I Schott communicated with Abbe, and the next year he removed to Jena, and the firm of Schott and Partners was born.

In the first catalogue of the Jena Glass Works they write :- "The industrial undertaking here first brought into public notice and which has arisen out of a scientific investigation into the dependence between the optical properties and the chemical composition of solid amorphous fluxes was undertaken by the undersigned (Schott and Abbe) in order to discover the chemicophysical foundations of the behaviour of optical glass." The inquiry was aided by large grants from the Prussian Minister of Education. The practical result is seen in the catalogue of the Jena firm and the enormous export of German optical goods.

Nor is this all, for in virtue of the distribution of profits settled by the scheme of the Carl Zeiss Stifting, drawn up by Abbe some years ago and ratified by the Bavarian Government, the University of Jena alone has received a sum approaching roo, oool. Abbe's work at Jena is perhaps the most striking illustration of the way in which progress depends on the cooperation of science and experience. One could give statistics to illustrate the truth of this and the important effect it has had on German trade and prosperity. They are hardly necessary; the facts are patent, and their cause well known to all who care to inquire. We can progress too if we follow the path laid down for us of old by Newton, Young, Herschel, Airy, and the others of whom I have spoken.

Exhibition of Optical and Scientific Instruments.

The exhibition of optical and scientific instruments which is being held during the present week at the Northampton Institute, Clerkenwell, E.C., in connection with the optical convention, presents many features of interest, and all who have had any experience in the use of an optical instrument, from the wearing of a pair of spectacles to the handling of an accurate-spectrometer, will find something to repay the trouble of a visit to Clerkenwell, still the centre of the optical industry. While the number of actual novelties offered is not, perhaps, very large, there are few classes of instruments unrepresented and though the names of certain important firms are conspicuously absent from the list of exhibitors, the exhibition as a whole may be taken as well representative of the No. 1857 , VOL. 72$]$ activities of the British manufacturers of optical and other scientific instruments.

In the main of an optical character, the scope of the exhibition has been extended to cover such other scientific instruments as are usually manufactured by optical instrument makers. Meteorological instruments and thermometers, mathematical and drawing instruments and calculating machines, and laboratory apparatus generally, are thus included. Electrical measuring instruments, however, are not shown. It is for many reasons to be regretted that the exhibition has been confined to the work of British makers; a foreign section would have had much interest for the ordinary visitor, and would have been of great educational value both to the British manufacturer and his competitors; we understand, however, that the limitation was dictated by considerations as to space, and the necessity of restricting the magnitude of a somewhat novel undertaking.

In the catalogue which has been prepared in connection with the exhibition, the convention committee is to be congratulated on having produced a volume which should be of considerable value as well to the user of scientific instruments as to the firms whose instruments are there described. The volume is not confined to apparatus actually exhibited; the aim has been to provide a convenient work of reference generally descriptive of the productions of British firms, and in which particulars as to the types offered by different makers of any special instrument may be readily found. To this end the instruments have been arranged in classes, which are in many cases further subdivided, and in addition to a table of contents; an alphabetical list of exhibitors, with general information as to their manufactures, and an index of instruments have been provided. A short introduction to each class furnishes some particulars as to the instruments included thereunder, with notes as to recent advances in the mode of construction.

In class i., tools and materials, the most interesting exhibit is that of Messrs. Chance Bros., which includes some varieties of optical glass only quite recently produced by the firm, and not previously shown. Some special opal glass of low coefficient of expansion for speculum dises is also exhibited. Messrs. Jas. Powell and Sons, of the Whitefriars Glass Works, show specimens of glass for thermometers and other purposes. Tools for lens grinding, and exhibits illustrating processes of manufacture, are shown by Messrs. Geo. Culver and other firms.

Class ii., simple elements and instruments, includes some accurate glass work by Messrs. A. Hilger, while Lord Blythswood shows specimens of his diffraction gratings ruled on speculum metal, 14,400 lines to the inch, up to a length of 6 inches. Replicas of Rowland gratings, with spectroscopes of various forms in which they are employed, are shown by Mr. T. Thorp, of Manchester.

Class iii., astronomical instruments, and class iv., nautical instruments, are by no means representative of the best English work, and it is to be regretted that the catalogue is here so meagre.

In class v., surveying instruments, on the other hand, few firms of importance are omitted, and some excellent work is shown. In particular may be mentioned the Wells theodolite of Messrs. Elliott Bros., which embodies several novel features; Messrs. Joseph Casartelli and Son, of Manchester, also show instruments of somewhat special pattern. Messrs. W. F. Stanley, J. J. Hicks, and E. R. Watts and Son are well represented. The chief characteristics of the more modern instruments are the use of larger and more powerful telescopes, and the increased accuracy of graduation.

Class vi. is devoted to range finders and heliographs, and the exhibits of most interest are the naval and field range finders of Messrs. Barr and Stroud, and the stereoscopic range finder of Prof. Geo. Forbes. Messrs. Ross, Ltd., show specimens of their new variable power gun sighting telescopes, in which by a simple device the power can be altered while the image remains always in focus on the cross wires.

Class vii. includes meteorological instruments and thermometers; and most of the well known makers have sent exhibits. In class viii., spectacles and eyeglasses, the exibits are also sufficiently representative of the best English 
work. An historical collection of no little interest is shown by Mr. M. W. Dunscombe, of Bristol.

In class ix., small telescopes and binoculars, are exhibited various patterns of prism binoculars by Messrs. Aitchison, Dallmeyer, Ross, Ltd., \&c. Messrs. Aitchison show also a field glass of novel type with a body machined from a solid casting, focusing being effected by moving each object glass in its own tube.

In class x., microscopes and accessories, the catalogue furnishes a very complete account of the English microscope as produced by the best makers, including binocular microscopes and various forms of instrument for special purposes. Photomicrographic cameras are shown by Messrs. Beck, and Ross, Ltd. Information of interest with regard to different types of photographic lenses is given in class xi., though too much space is perhaps devoted in the catalogue to illustrations of camera bodies.

In the careful classification and selection of instruments to illustrate the various types, class xii., optical projection apparatus, appears to us to be the most successful in the catalogue. The class includes an exhibit by Messrs. Chance Bros. of a complete lighthouse optical apparatus of the fourth order. Other exhibits of interest are $\mathrm{Mr}$. $\mathrm{R}$. W. Paul's projector lamps, the triple rotating lantern of Messrs. Newton, and animatographs by Messrs. Paul, the Prestwich Manufacturing Co., and J. Wrench and Son.

In class xiii., àpparatus for optical measurement; some new optical benches are shown by Messrs. Aitchison and Beck, and there are interesting exhibits from the Cambridge Scientific Instrument Co. and Messrs. Hilger. A half-shadow polarimeter is shown by Prof. Poynting, the half-shadow field being produced by the tilting of two glass plates forming $\mathrm{a}$ 'V between the polariser and analyser.

Under photometric apparatus the Ediswan Co. show specimens of Prof. Fleming's large bulb standard lamps, and various forms of photometer are exhibited by Messrs. Alex. Wright. Class xv. is devoted to ophthalmic apparatus, and includes a novel form of ophthalmoscope of British design and construction. The Cambridge Scientific Instrument Co. and Messrs. Griffin show laboratory apparatus under class xvi. Under class xvii., mathematical and drawing instruments, some new forms of slide rule are shown, including one with additional slides by Messrs. Davis, of Derby, and an optical slide rule with reciprocal division for determination of conjugate foci, \&c., by $\mathrm{Mr}$. A. Salomon, of Huddersfield. An arithmometer of English make is exhibited by Mr. S. Tate, and an adding machine by the Burroughs Adding Machine Co.

\section{UNIVERSITY AND EDUCATIONAL}

\section{INTELLIGENCE.}

CAMBridge.-Among the twelve distinguished men who will receive honorary degrees on June I4 only two are connected with scientific work. These are Commander R. F. Scott, R.N., of the Discovery, and Colonel Sir Francis E. Younghusband, K.C.I.E. The latter has been appointed Rede lecturer, and has chosen as his subject "Our True Relationship with India." The lecture will be delivered in the Senate at ri.3o a.m. on Saturday, June ro.

Mr. L. A. Borradaile, of Selwyn College, who is well known for his researches on the crustacea, has been appointed assistant secretary for lectures to the local examinations and lecture syndicate.

A university lectureship in mathematics will shortly be vacant owing to the resignation of Mr. G. B. Mathews, F.R.S., of St. John's College.

The special board for biology and geology has nominated Mr. J. J. Lister, Fellow of St. John's College, to occupy the university table at the laboratory of the Marine Biological Association at Plymouth for one month during the present year.

In spite of the efforts of the master of Pembroke, Prof. Ridgway and others to bring the work of the studies and examination syndicate to an end, the Senate decided by II2 votes to 99 that its deliberations should be continued. It seems evident that a majority of residents is in favour of some change.

NO. $185 \%$, vOL. 72$\rceil$
The syndicate entrusted with the building of the new medical schools has exceeded the sum granted by Grace of the Senate by $257 \mathrm{Il}$. 15s. 6d. It is now asking for authority to pay this amount, and for $920 l$. for the completion and fitting of the Humphry Museum, and $380 l$. for extra fittings and furniture in the departments of surgery, midwifery, medicine, pharmacology, and pathology.

I'HE Pioneer Mail states that a grant of 10,000 rupees has been made to the Victoria Diamond Jubilee Technical Institute of Lahore for buildings and appliances. A permanent grant of roo rupees a month has also been made, and the assistance thus given will enable the governors to complete the equipment for the teaching of practical and applied chemistry.

At a meeting of the School Nature-Study Union held at the College of Preceptors on Friday, a paper was read on the training of teachers for nature-study by Miss $R$. Lulham. In it the necessity for a proper ground work was brought out, and during the discussion which followed a resolution was passed urging upon the London County Council the need of providing classes for those who have to teach nature-study, and suggesting that a wild garden for their benefit should be established in at least one of the London parks, in which the botanic gardens arranged for the students of systematic botany have already proved so useful.

We have received the first number of the University Review, which is published by Messrs. Sherratt and Hughes at $6 d$. net. Dr. Bryce contributes an introductory note on the university movement, and among other articles dealing with many aspects of higher education may be mentioned one by Prof. Arthur Schuster, F.R.S., on "Universities and Examinations," and another by 'Sir Oliver Lodge, F.R.S., on "Questions for Discussion." Prof. Schuster formulates briefly what the aims of an ideal university should be, and proceeds to divide its work into two parts. These are the acquisition of knowledge and the power of applying it. The second part of the work of the university is the higher, and is what is required for success in life. Prof. Schuster says that it can be taught, and therefore should be taught, in the university, but that this power of applying knowledge cannot be tested satisfactorily by examination. He then considers exhaustively the function of examinations, and shows what they are capable of doing and the qualities they are incompetent to gauge. $\mathrm{He}$ concludes by remarking that when a student "has shown that he deserves a degree, it is right and proper that an opportunity shall be given him to develop his special powers and to distinguish himself:" Prof. Schuster makes a proposal to secure this by giving a year which is absolutely at the student's disposal to be used under the guidance of his teachers as he thinks fit. Sir Oliver Lodge discusses the possibility of introducing a change in the "time of year when examinations should be held:-whether candidates should be examined directly lectures cease, and before Session ends; or whether they should be given time for revision and digestion, and perhaps oblivion, and be examined just before a new Session commences." The review also supplies full information of current events in British and foreign universities.

\section{SOCIETIES AND ACADEMIES. LoNDON.}

Royal Society, March 30._-"The Determination of the Specific Heat of Superheated Steam by Throttling and other Experiments." By A. H. Peake. Communicated by Prof. Ewing, F.R.S.

This paper is an account of original investigations undertaken to determine the specific heat of superheated steam. Two methods have been followed:-( $\mathrm{r}$ ) the throttling or wire-drawing of steam to obtain the law connecting the variation of temperature with pressure, for constant total heat; (2) the direct heating of a current of steam by electrical means.

An account of an investigation on the same lines as method (I), by Mr. J. H. Grindley, was published in the Philosophical Transactions of the Royal Society, A, vol. 